\title{
Current Issues in Biowaivers and Biosimilars
}

\section{Laszlo Endrenyi*}

Department of Pharmacology and Toxicology, University of Toronto, 1 King's College Circle, Toronto, ON, M5S 1A8, Canada

\section{Background}

Biowaivers and biosimilars are important topics being discussed when patents of originator drug products by brand-name companies expire and the regulatory approval of generic formulations is considered.

If, under certain conditions, a biowaiver is granted then a generic product may be approved on the basis of comparative in vitro dissolution studies instead of requiring in vivo investigations of bioequivalence $[1,2]$.

The main emphasis of the Conference was on biosimilars. They are generic formulations which are expected to be highly similar with the originator biologic product. Regulatory guidelines, e. g. by the European Medicines Agency (EMA) of the European Union, Health Canada and the World Health Organization (WHO) discuss the determination of biosimilarity [3-5].

In the United States, draft guidances were published only recently [6-8]. They implemented and expanded on the 2009 Biologics Price Competition and Innovation Act (BPCI Act) which provided the legal basis of the regulations [9].

\section{Biowaivers}

Lisa J. Murray (Absorption Systems, Exton, PA) reviewed, in a keynote presentation, the Biopharmaceutics Classification System (BCS). It has been incorporated into regulatory guidances (e,g, [1,2]). Based on the work of Amidon et al. [10], BCS allows drug companies to obtain waivers ("biowaivers") of clinical bioequivalence studies. They can be applied to immediate-release, solid dosage forms notably when they have high solubility and high intestinal permeability (Class 1 ). Procedures of in vitro solubility, permeability and dissolution studies were presented. In particular, the use of Caco- 2 cell lines was discussed with a multitude of diverse and challenging compounds.

\section{Legal Issues of Biosimilarity}

Paul A. Calvo (Sterne, Kessler, Goldstein \& Fox,Washington, DC), in his keynote presentation, outlined effects of the America Invents Act which has introduced the most significant changes to patent law in fifty years. The new proceedings instituted by the Act are dealt with at the US Patent and Trademark Office (PTO). They may provide earlier resolution for originator and biosimilar conflicts through expedited validity determinations and also bring about settlements that could avoid more costly litigation altogether. Proceedings of the Inter Partes Review were discussed in detail. It is conducted at the PTO where the validity of a patent can be challenged on the grounds of prior publication.

Brian R. Dorn (Barnes \& Thornburg, Minneapolis, MN) discussed the role of patents in biosimilars and biobetters. He noted that the approval pathway of the BPCI Act provides a 12-year exclusivity fo the originator/reference product. This may outlast the patent term, even if it is extended. The Act provides also a patent litigation scheme to determine infringement.

Bryan H. Vogel (Robins, Kaplan, Miller \& Ciresi, NY) outlined in greater detail the litigation process and the required systems of disclosures and counter-disclosures. The legal framework leaves several questions unclearly defined which will have to be resolved with experience. Susan Finston (Finston Consulting, Washington, DC) discussed the exclusivity periods under the BPCI Act. These provide opportunities for increased innovation together with social benefits from the biosimilar pathway [11].

D’vorah Graeser (Graeser Associates, Chicago, IL) observed that the BPCI Act and the accompanying FDA regulations may expose trade secrets of both originators and biosimilar applicants. The Act requires that information be exchanged between the two parties. This means that the loss of trade secret rights may be a very real threat. Consequently, the current FDA process is unsettled and the effects of the patent process are unclear.

\section{Regulatory Issues of Biosimilarity}

Jun Wang (Duke University, Durham, NC) reviewed procedures for the assessment of biosimilar products which had been described in recent guidelines issued by various regulatory authorities [3-5,7-9]. The data requirements, choice of the reference product and scope are at times different but the basic concepts and main principles are similar for approving biosimilars [12].

Laszlo Endrenyi (University of Toronto, ON, Canada) discussed statistical issues on the evaluation of the similarity and interchangeability of biologics. Unlike in the case of small molecules, the two levels of regulatory approval are distinct for biologics. The BPCI Act raises formidable obstacles to the interchangeability of biologic products [13].

Ben Kaspar (MMS Holdings, Canton, MI) noted that a recent FDA Draft Guidance [7] emphasized the need for scientific justification in the various components of submissions. Therefore, effective scientific dialog with the FDA should be conducted at various stages of the process.

\section{Development of Biosimilars}

William Velander (University of Nebraska, Lincoln) described transgenic blood proteins which could become an abundant source for next generation therapies with worldwide availability. They would provide, from cultured animal cells, non-intravenous therapies that simultaneously achieve immune toleration with longer lasting activity.

Both P. Bailon (Bailon Consultants) and H. Zhao (Enzon Pharmaceuticals, Piscataway, NJ) discussed the application of PEGylation (the covalent attachment of polyethylene glycol) to

*Corresponding author: Laszlo Endrenyi, Department of Pharmacology and Toxicology, University of Toronto, 1 King's College Circle, Toronto, ON, M5S 1A8, Canada, Tel: 1-416-925-3779; Fax: 1-416-322-6375; E-mail: endrenyi@utoronto.ca

Received November 26, 2012; Accepted November 27, 2012; Published November 29, 2012

Citation: Endrenyi L (2012) Current Issues in Biowaivers and Biosimilars. Clin Exp Pharmacol 2:e117. doi:10.4172/2161-1459.1000e117

Copyright: @ 2012 Endrenyi L. This is an open-access article distributed under the terms of the Creative Commons Attribution License, which permits unrestricted use, distribution, and reproduction in any medium, provided the original author and source are credited. 
biosimilars. Novel releasable PEG linkers allow the programmed release of intact, fully functional drug molecules.

Kelly S. Colletti (Charles River Preclinical Sciences, NV) discussed strategies for the development and validation of immunogenicity assays to support preclinical and clinical biosimilar programs. The respective merits were analyzed of a single- or two-assay approach for the comparison of immunogenicity rates between the biosimilar and innovator products, subject of much current debate,

Melody Sauerborn (TNO Triskelion, Zeist, The Netherlands) considered the use of human transgenic animal models for immunogenicity testing and their value for comparative studies of biosimilars. The animals are immune tolerant for the protein drug of interest and are useful tools to investigate the immunogenic potential of protein drugs and the factors influencing immunogenicitiy.

Luke H. Bradley (University of Kentucky College of Medicine, Lexington, KY) discussed high-quality combinatorial approaches for protein discovery and development. Platform technologies productively introduce modified changes into a protein structure. They can yield large collections of folded, soluble, highly-expressible, and functionally-novel proteins [14].

Paul Rösch (University of Bayreuth, Germany) described a structure-based design of an enterotoxin which is responsible for many cases of acute secretory diarrhea. The chimeric protein prouro-STh was expressed in E. coli and extensively purified. The scheme of expression is cost-efficient and scalable.

Fuad Fares (University of Haifa, Israel) stated that the clinical use of many peptides is limited by their short half-life. To overcome the problem, the signal sequence of O-linked oligosaccharides was ligated to the coding systems of hormones. The strategy may allow the reduction of drug dose and of the number of injections of recombinant proteins

\section{Analytical Strategies}

C. Patrick McAfee (SACHEM, Austin, TX) noted the importance of analytical characterization of biologics as emphasized by recent regulatory guidances $[3,8]$. Displacement chromatography can efficiently identify and isolate variants of biologics. Carmine Lanni (Bioanalytical Development Services) discussed further the complex bioanalytical assessments which become highly refined and sensitive.

Rafiq Islam (Celerion, Lincoln, NE) illustrated challenges of pharmacokinetic and immunogenicity assays which should be sensitive, robust, and comparable for the two drug products.

David Goodall (Paraytec, York, UK) presented methods for the measurement of protein size, aggregate levels and viscosity. The methodology is well suited for the rapid characterization of formulated proteins and biopharmaceuticals, including biosimilars.

\section{Plant-produced Biosimilar Products}

Michael D. McLean (PlantForm, Guelph, ON, Canada) discussed, in a keynote lecture, the production of biosimilar protein-based drugs in plant bioreactors. These reactors offer many advantages for the pharmaceutical industry, including lower upstream production costs, speed of manufacturing, lack of human or animal pathogens, the eukaryotic production of proteins with desired structures and functions, indefinite scalability, and ease of handling. Challenges include the higher downstream processing and purification costs, and the requirement for modifying plant-specific post-translational glycosylations. - In a second lecture, Dr. McLean presented a plantbased production and preclinical analysis of biosimilar Trastuzumab. The drug has identical sequence with Herceptin. It is over $99 \%$ pure, no predicted immunogenicity, and has in vitro and in vivo biosimilar activity.

Kathleen L. Hefferon (University of Toronto, ON, Canada) described plant expression platforms for human therapeutic proteins. Large quantities of vaccines and therapeutic proteins can be produced in a safe and effective manner. They are easy to store, require fewer long and expensive purification steps and lack the containment risks associated with proteins produced in animal and bacterial expression systems [15].

\section{Aggregation, Immunology}

Veysel Kayser (Massachusetts Institute of Technology, Cambridge, MA) presented mechanistic insights into protein aggregation, and the development of rational approaches and predictive tools for the stabilization of biopharmaceuticals. The aggregation of monoclonal antibodies occurs, with non-Arrhenius kinetics, via a partially unfolded conformation. The aggregation profile is somewhat similar to that of amyloidal proteins.

Melody Sauerborn (TNO Triskelion, Zeist, The Netherlands) reviewed immunological aspects of the formation of anti-drug antibodies against aggregated protein drugs [16]. Biosimilars could involve more aggregation and a higher occurrence of immunogenicity.

\section{Therapeutics with Biosimilars}

Patricia B. Pelegrini (BioLife Brazil) presented the development of recombinant glucagon mainly for the treatment of diabetes and also for other applications including as a bronchodilator and in intestine radiography.

Inge Thomsen Bernstein (Hvidovre University Hospital, Denmark) described the development of

an electronic register of families with colorectal cancer. The system increased reporting to a central database by almost $200 \%$.

\section{Process Control, Manufacturing}

Indu S. Javeri (CuriRx, Andover, MA) discussed the role of process control in mitigating the risk associated with the manufacturing of biosimilars. The importance of stability fingerprinting was emphasized as a basis for rational dosage form and formulation development.

Amal A. Elkordy (University of Sunderland, United Kingdom) talked about the effects of spray drying and freeze drying technologies and polymers on the integrity and biological activity of proteins. Notably, polyvinyl pyrrolidone maintained the integrities and biological activities of lysozyme and trypsin during stresses of drying and also after storage at high relative humidity and temperature [17].

\section{Markets for Biosimilars}

Gustavo Helguera (University of Buenos Aires, Argentina) reported on the growth and development of biologics and biosimilars in Argentina. Today, there are nearly 30 biopharmaceutical firms with representations from the top ten pharmaleaders in the world.

Leandro Mieravilla (Cassara Biotech, Montreal, Canada) reviewed the growing worldwide market for biosimilars.

Altogether, the Conference exposed the wide range of issues which 
should be thought about and further developed. The exchanges of ideas were highly interesting and illuminating.

\section{Financial Disclosure}

The author is a member of a Statistical Science Advisory Board which is supported by Amgen Inc. but is scientifically and operationally at arm length.

\section{References}

1. FDA (2000) Guidance for Industry: Waiver of In Vivo Bioavailability and Bioequivalence Studies for Immediate-Release Solid Oral Dosage Forms Based on a Biopharmaceutics Classification System. US Food and Drug Administration, Rockville, MD, USA.

2. WHO Expert Committee on Specifications for Pharmaceutical Preparations (2006) WHO expert committee on specifications for pharmaceutical preparations. Fortieth report. World Health Organ Tech Rep Ser 937: 1-461.

3. EMEA (European Medicines Agency) (2005) Guideline on Similar Medicinal Biological Products. Committee for Medicinal Products for Human Use, London, United Kingdom.

4. WHO (2009) Guidelines on Evaluation of Similar Biotherapeutic Products (SBPs). World Health Organization, Geneva, Switzerland.

5. Health Canada (2010) Guidance for Sponsors: Information and Submission Requirements for Subsequent Entry Biologics (SEBs). Health Products and Food Branch, Ottawa, Ontario.

6. BPCl Act (2010) Biologics Price Competition and Innovation Act of 2009 Federal Register; HR 3590-686-702.

7. FDA (2012) Draft Guidance for Industry - Scientific Considerations in Demonstrating Biosimilarity to a Reference Product. Center for Drug Evaluation and Research and Center for Biologics Evaluation and Research, US Food and Drug Administration, Rockville, Maryland, USA.
8. FDA (2012) Draft Guidance for Industry - Quality Considerations in Demonstrating Biosimilarity to a Reference Protein Product. Center for Drug Evaluation and Research and Center for Biologics Evaluation and Research, US Food and Drug Administration, Rockville, Maryland, USA.

9. FDA (2012) Draft Guidance for Industry - Biosimilars: Questions and Answers Regarding Implementation of the Price Competition and Implementation Act of 2009. Center for Drug Evaluation and Research and Center for Biologics Evaluation and Research, US Food and Drug Administration, Rockville, Maryland, USA.

10. Amidon GL, Lennernäs H, Shah VP, Crison JR (1995) A theoretical basis for a biopharmaceutic drug classification: the correlation of in vitro drug product dissolution and in vivo bioavailability. Pharm Res 12: 413-420.

11. Epstein RA (2011) The constitutional protection of trade secrets and patents under the Biologics Price Competition and Innovation Act of 2009. Food and Drug Law J 66: 285-328.

12. Wang J, Chow SC (2012) On the regulatory approval pathway of biosimilar products. Pharmaceuticals 5: 353-368.

13. Endrenyi L, Chang C, Chow SC, Tothfalusi L (2012) On the interchangeability of biologic drug products. Stat Med

14. Bradley LH, Bricken ML, Randle C (2011) Expression, purification, and characterization of proteins from high-quality combinatorial libraries of the mammalian calmodulin central linker. Protein Expr Purif 75: 186-191.

15. Hefferon KL (2012) Plant virus expression vectors set the stage as production platforms for biopharmaceutical proteins. Virology 433: 1-6.

16. Sauerborn M, Brinks V, Jiskoot W, Schellekens H (2010) Immunological mechanism underlying the immune response to recombinant human protein therapeutics. Trends Pharmacol Sci 31: 53-59.

17. Elkordy AA, Forbes RT, Barry BW (2008) Study of protein conformationa stability and integrity using calorimetry and FT-Raman spectroscopy correlated with enzymatic activity. Eur J Pharm Sci 33: 177-190. 